\title{
Arte y Arquitectura: los procesos interpretativos inmersos en la creación de una obra
}

\author{
Art and Architecture: \\ The Interpretation Processes Immersed \\ in the Creation of a Work
}

Adriana Masís

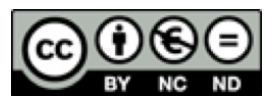

Esta obra está bajo una licencia Creative Commons Reconocimiento-No comercial-Sin Obra Derivada 
Artículos

\title{
Arte y Arquitectura: los procesos interpretativos inmersos en la creación de una obra ${ }^{1}$ Art and Architecture: The Interpretation Processes Immersed in the Creation of a Work
}

\author{
Adriana Masís ${ }^{2}$ \\ Universidad de Costa Rica \\ adrianama59@yahoo.es
}

Recibido: 12 de enero de 2017 Aprobado: 06 de mayo de 2017

\section{Resumen}

Se ha dicho en algunos casos que la arquitectura es un arte o, por ejemplo, que es una escultura habitable. Tal cosa, continúa en discusión. Lo que es cierto, es que en el mundo de la arquitectura y el arte; especialmente ahora con el vicio por lo instantáneo y una sociedad que se preocupa más por las respuestas que por las preguntas; cada obra se muestra como si desde siempre hubiera sido la mejor solución o el resultado esperado. Se ocultan los procesos y se muestran los productos, súbitamente. Esta investigación nos remite a explorar la existencia de una serie de procesos interpretativos previos a la creación, que atienden al reconocimiento de nuestra capacidad de asombro, experimentación y comunicación de descubrimientos; como medios para la creación de propuestas artísticas significativas.

Palabras clave: proceso creativo; arte; arquitectura; interpretativo; experiencia

1 Este artículo surge a raíz del desarrollo y elaboración de la tesis titulada Hermenéutica de la Arquitectura: la relación sujeto-espacio interpretada desde los fenómenos poéticos y paradigmáticos, en donde a través del diálogo entre arte, arquitectura, literatura y filosofía, se vislumbran una serie de procesos interpretativos regularmente despreciados en las etapas previas a la materialización de una obra.

2 Licenciada en Arquitectura por la Universidad de Costa Rica. Arquitecta e Investigadora independiente. 


\begin{abstract}
:
It has been said in some cases, that architecture is an art, or for example, that it is an inhabitable sculpture. Such thing is still in discussion. The fact is that in the world of arts and architecture; especially with our current vice for the instantaneous and a society that worries more for the answers than for the questions; each oeuvre is shown as if it had been, since always, the best solution or the expected result. Processes are hidden and products are shown, abruptly. This investigation leads us to explore the existence of a series of interpretative processes, which take place before material creation and attend the acknowledgement of our capacity to wonder, to experience and communicate discoveries; as the means to create significant artistic proposals.
\end{abstract}

Keywords: creative process; art; architecture; interpretative; experience 


\section{Sobre el Arte y la Arquitectura}

La Arquitectura comparte con el Arte una serie de sensibilidades y búsquedas creativas que, desde muchas de sus manifestaciones como: la pintura, la literatura, la escultura y otras, modifican nuestra vivencia del mundo y responden a todo un proceso de interpretación que se ha visto desestimado ante la mercantilización de lo artístico. Vemos los croquis de la primera idea de un arquitecto o vemos inclusive a los artistas y poetas, que pareciera que mágicamente consiguen envolverse en un torbellino de ideas que los lleva a diseñar, pintar y escribir fluidamente como si fuera algo completamente natural, fácil y espontáneo. Nosotros, al vernos desprovistos de esa prodigiosa facultad, nos intimidamos al no lograr saturar nuestros lienzos; pero $¿$ alguna vez reflexionamos sobre la obra antes de enfrentarnos al papel? Esto quiere decir que probablemente en nuestro apuro por declarar nuestras intenciones y demostrar nuestras capacidades, acudimos al papel, antes de tiempo.

Nos hemos enfocado exclusivamente en exhibir los productos (el resultado final), dejándose de lado la noción de proceso, al cual habría que prestar atención. Si vemos el proceso creativo y el diseño en términos de la interpretación que los antecede, lo que hacemos es librar al Arte y la Arquitectura de toda una serie de aspectos técnicos y constructivos que, si bien es cierto son parte fundamental en la ejecución de una obra, en ocasiones obstaculizan la comprensión del acto creativo, como un acto sensible, que responde a una convivencia y a un contexto. Además, dicho acto no es construido exclusivamente por los artistas y arquitectos, sino por todos los sujetos que conjuntamente componen la sociedad.

Desde la Arquitectura, en un breve ensayo escrito por Heidegger bajo el título El arte y El Espacio el autor dice: "el espacio es ocupado por la figura plástica y queda moldeado como volumen cerrado, perforado y vacío. [Y agrega:] ¿Acaso esta corporeiza el espacio? ¿Se adueña la plástica del espacio? ¿Es una dominación del espacio?” (Heidegger, 2009 p. 13). De ahí se desprende el pensamiento de que la corporeización del espacio es la que permite el habitar, pues a su vez corporeiza "la verdad del ser" (Heidegger, 2009, p. 32), o sea, su existencia. Entonces, el espacio para la Arquitectura es de primera mano, una cosificación del vacío, pues nos lo hace evidente al colocar algo en él. Pero ¿sería esa la única realidad posible sobre el espacio? “¿puede valer el espacio proyectado en términos técnicos y físicos como el único espacio verdadero?” (Heidegger, 2009 p. 16) ¿puede valer la obra artística creada, y tangible a los sentidos, como lo único verdadero?

Más adelante en el texto, queda entendido que esto es simplemente lo más ordinario y accesible al entendimiento. Ahí es donde se rescata la concepción de la obra, como una lectura metafísica que trasciende la materialidad y todo lo que creemos evidente por medio de nuestros sentidos y preceptos sociales, y se genera un amplio espectro de simbolismos y significados 
que afectan nuestra percepción individual del mundo. Desde esta perspectiva, dejaríamos de apelar a los productos del Arte y la Arquitectura como objetos en sí, para entender los objetos como fenómeno que nos afecta y nos proporciona experiencias. Entonces, a través de esta sensibilidad, surge un reconocimiento de aspectos humanizadores que nos sugieren hacer una lectura que trascienda lo tangible, en donde tengan cabida otros valores como la cotidianidad, la vida en sociedad y la habilidad interpretativa.

\section{El proceso interpretativo como elemento inmerso en la creación de una obra}

A medida que los días pasan, se crean ciertas rutinas y modos de pensamiento que se vuelven recurrentes; a los cuales se les tiende a englobar bajo la idea del "transcurso de la vida cotidiana". Es durante este transcurso que cada disciplina va reconociendo su lugar dentro de la sociedad y, por lo tanto, conociéndose y reconociéndose. Hecho de gran valor, pero de productos limitados por el enfrascamiento de las ideas dentro de una cotidianidad que se concibe como "una serie de hechos ordinarios reiterativos".

Ante tal situación, cabe preguntarse: ¿qué pasaría si el "transcurso de la vida cotidiana" fuera ahora reconocido como el "transcurso de una inquietud de sí"? Probablemente, eso permitiría a las disciplinas no solo conocerse a sí mismas, sino, ocuparse de sí; esto es, dejar de visualizarse hacia el exterior como oferentes de respuestas a los fenómenos que se encuentran a su alrededor y comenzar a reestructurar el proceso previo a esas respuestas. El cual se encuentra en el interior de lo que se suponía que ya era un proceso preestablecido para cada disciplina y del que por lo tanto nunca se habla. Jean Nouvel, refiriéndose a la serie de conversaciones que un arquitecto tiene con un cliente, llega también a pensar que existen cosas que se quedan inmersas dentro de lo que no se dice, pero reconoce que son justamente esas, las más vitales de todas las cosas. En sus palabras:

Siempre queda una parte que es del orden de lo no-dicho, eso forma parte del juego. Y, en un plano ético, eso no-dicho es una cosa aparte, algo que no va en contra de lo que uno va a vender o a intercambiar, en contra de las nociones económicas, pero significa algo vital (Baudrillard \& Nouvel, 2001, p. 17).

De hecho, este fenómeno no es algo exclusivo de la Arquitectura, sino que sucede en muchos ámbitos, por ejemplo, en el conocimiento popular que se plasma en los refranes (paradójicamente también llamados: "dichos"). Los cuales muestran cómo el mensaje esencial a transmitir está en la dimensión de lo-no-dicho, pero se valen de todo lo que está evidente en la vida diaria para establecer su razón de ser. Ya en el saber popular, desde los grandes mitos sucedidos in illo tempore hasta los refranes que siguen presentes en nuestros días, es reconocido que sin importar si se trata de conocimientos que se construyeron entre verdad y fantasía, 
un mito o un refrán como saberes compartidos oralmente por el pueblo, están creados de una forma que es más lo-no-dicho que lo-dicho. Sin embargo, las personas entienden su aplicabilidad, moraleja o sentido, gracias a que su construcción evoca a consejos basados en la experiencia popular y reflejan indirectamente un hecho considerado verdadero por la sociedad al referirse a actividades de lo cotidiano, las cuales son transformadas con audacia en ideas esenciales que deben ser inferidas para revelar un mensaje.

Así, por ejemplo, si observamos grosso modo la visión de la hermenéutica desde algunos de sus principales expositores, nos encontramos con una fuerte tendencia a pensar, en términos de la experiencia, la búsqueda de la verdad y la influencia de lo social y lo cotidiano. En ese sentido y respecto a lo dicho en nuestra analogía sobre el saber popular, poner en práctica la hermenéutica viene a ser la toma de consciencia sobre todo aquello que sucede cotidianamente y de lo que todos los sujetos participan, pero traducido a la inversa de los mitos y refranes. Es decir, construyendo desde los fenómenos no-dichos un reflejo o reconstrucción que activa expresamente un nuevo conjunto de ideas esenciales, ahora visibles y "desocultadas".

Efectivamente, esto puede resultar extraño a la Arquitectura, ya que lo que convencionalmente se toma en consideración en el proceso creativo de la obra es lo tangible y el cumplimiento de las preestablecidas necesidades mínimas. Mientras que, tal y como lo explica Hall, 'todo lo que pase de la necesidad mínima suele considerarse 'superfluo'. ... [A lo que agrega para defender su argumento] Podemos medir con una cinta si un hombre puede o no alcanzar algo, pero hemos de aplicar una diferente serie de normas para apreciar la validez de la sensación de apretura que un individuo pueda tener" (Hall, 2003, pp. 69-70). Esta manera de ver la Arquitectura nos manifiesta que no es suficiente con tener códigos, reglamentaciones, estudios científicos y demás saberes institucionalizados a la mano para garantizar la satisfacción y el verdadero sentir del habitar que una persona pueda tener, lo que deja entrever que Hall sugiere el reconocimiento y surgimiento de otros medios para comprender el comportamiento humano.

Ante esto, Augé reafirma: "el mundo de la supermodernidad no tiene las medidas exactas de aquel en el cual creemos vivir, pues vivimos en un mundo que no hemos aprendido a mirar todavía. Tenemos que aprender de nuevo a pensar el espacio" (2000, p. 42). Tal y como lo hace el artista James Turrell, quien toma los conceptos de luz y espacio como elementos fundantes de sus obras, proponiendo una versión artística sobre nuestra actual discusión que contempla la posibilidad de ver el espacio desde una nueva perspectiva. Él ha creado un espacio reconocido como un fenómeno que, una vez terminado, será culminante en el mundo del Arte: el Roden Crater. Un portal para observar el tiempo, la luz y el espacio, en el cual el artista se apropia de un concepto y luego lo brinda para ser visto y convertirse en la experiencia de otro. 
Dicho observatorio mezcla la idea de las recámaras y pasadizos antiguos, con lo futurístico, pero lo que provoca la fascinación por este proyecto de "landart" es la sensación de límite espacial similar a lo que logró Malévich con su "cuadrado blanco sobre fondo blanco". Se considera el Roden Crater una obra capaz de captar el sentido de límite (borde, margen) porque una vez que las personas hayan descendido al fondo del cráter y volteen hacia arriba se persigue infundirles la sensación de observar la esencia de algo y ese algo es el cielo enmarcado en un círculo como una cuestión ajena (externa a nosotros), pero de la que simultáneamente nos sentimos ligados internamente al ser un fenómeno cotidiano, llevado ahora a lo extraordinario gracias a la habilidad de Turrell, de colocar al sujeto en un límite interno-externo que le da rienda suelta a la reflexión sobre la existencia.

Figura 1. Roden Crater: Desierto Pintado, Norte de Arizona, Estados Unidos, 1960-2016

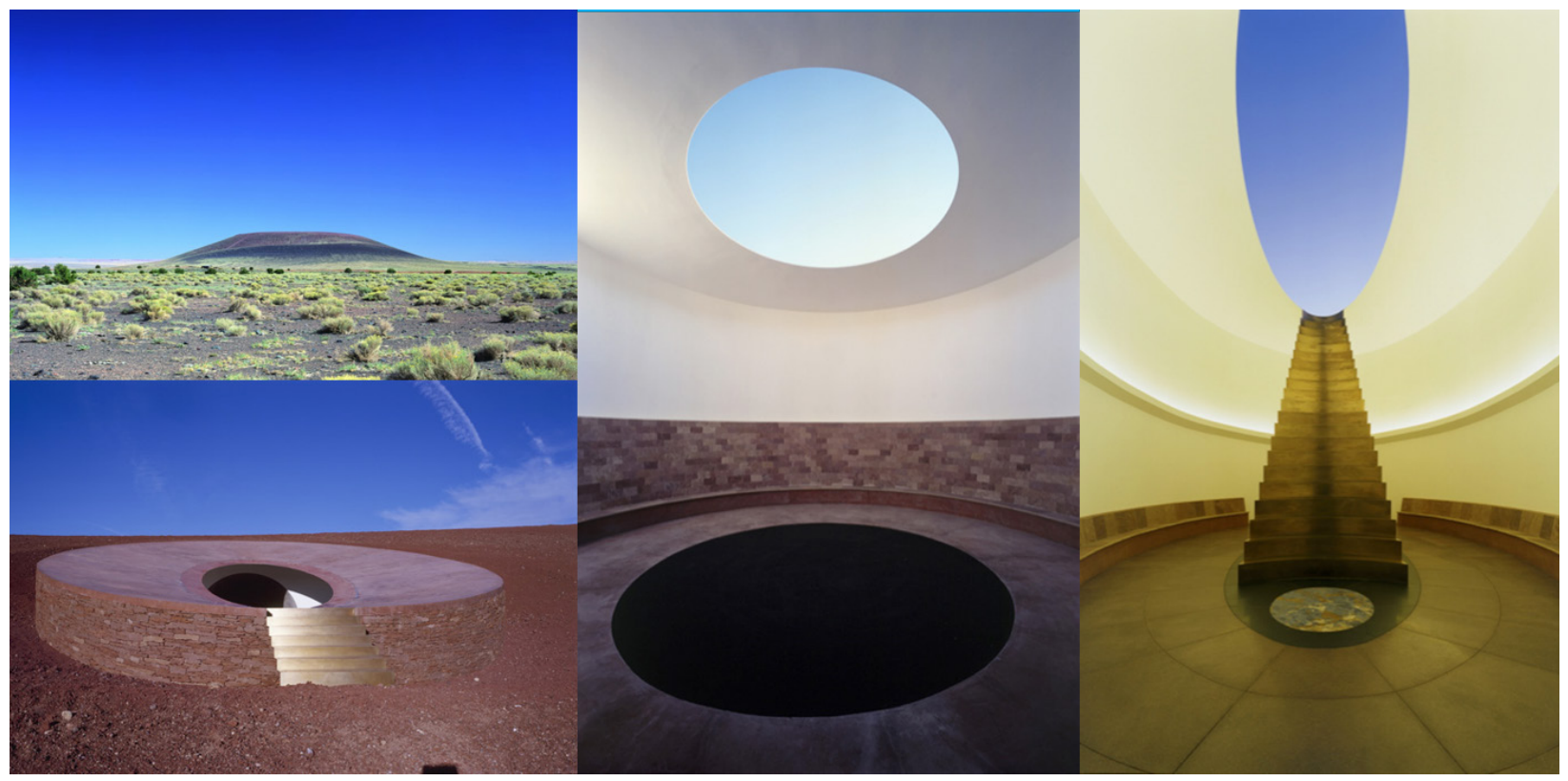

Fuente: Go See- Germany: James Turrell's "The Wolfsburg Project," at Kunstmuseum-Wolfsburg through April 5th, 2010 (10 diciembre 2009).

Ahora bien, dejando de lado esta aplicación artística sobre el cambio de perspectiva ante el asunto del espacio, también es posible la invención de nuevos medios que analicen la parte sensible y perceptual de la Arquitectura sin caer en el dogma de "necesidades y dimensiones mínimas". De hecho, en un apartado de las conversaciones entre Baudrillard y Nouvel, titulado "Metamorfosis de la Arquitectura", se plantea que es posible tratar con la crisis actual de la Arquitectura y convertir los asuntos del espacio en algo positivo: 
tomando en cuenta las cosas que no fueron consideradas con anterioridad, que a menudo son del orden del azar, e inventando estrategias de valorización, una poética de las situaciones ... Es una estética de la revelación, una forma de tomar parte del mundo y decir: "Me lo apropio y lo brindo para ser visto de otra forma" (Baudrillard \& Nouvel, 2001, p. 33).

Esto es justamente lo que la hermenéutica hace, un ejercicio de apropiación de los textos para brindarlos nuevamente al mundo ya transformados en ideas distintas. Tal poética de las relaciones a la que hacen referencia los autores depende del desarrollo de las habilidades interpretativas en los arquitectos y justifica el despliegue de la crisis arquitectónica como un hecho que se mantendrá constante a no ser que surja la invención de algo distinto a lo que ya estaba asumido, inadvertido, desmerecido y obviado. Sobre esto nos confirma Vattimo:

La pregunta sobre "qué hacer" no se puede contestar con respuestas fundadas sobre cualquier esencia eterna, sino que solo puede dar lugar a una relectura del "dónde estamos" para entender - de forma arriesgada y con toda la incertidumbre de la interpretación- la dirección hacia dónde ir (Vattimo, 2007, p. 1).

En este caso, si confrontamos la Arquitectura y todo ejercicio creativo desde su definición, sus escenarios y paradigmas, podríamos concluir que ya hemos asumido el "donde estamos" a través de su relectura y ahora nos correspondería proponer y afirmar la nueva ruta de cada disciplina. Sin embargo, otros autores temen la pérdida de la esencia o verdad arquitectónica, al abrirse paso nuevos procesos e ideas. Por lo que surge la interrogante: “¿hay una verdad en la Arquitectura?” (Baudrillard \& Nouvel, 2001, p. 9). Esto se lo pregunta preocupado Baudrillard a Jean Nouvel ante el reconocimiento de la crisis arquitectónica; y a esto Nouvel responde con más preguntas, mientras deja implícito que esa verdad existe, pero excede lo que hasta ahora se ha entendido como el fin de la Arquitectura.

En resumen, la visión que expone Nouvel sobre el cambio en nuestra manera de ver la Arquitectura establece una correspondencia con nuestro concepto de colocarse sobre el margen -como en el Roden Crater-. Al estar la verdad de la Arquitectura en un plano que sobrepasa a la disciplina misma, se establece que el momento en el que la Arquitectura comienza a convertirse en otra cosa distinta a lo que se ha entendido siempre como Arquitectura, esto no la convierte en una disciplina distinta, sino que la lleva un paso más allá de lo que parecía estar destinada a ser. Es decir, ubicarse al borde del precipicio para cambiar de visión no la convierte en otra, sino que la hace trascenderse a sí misma.

No obstante, hacer una filosofía de la Arquitectura o una filosofía del Arte que contenga los argumentos para legitimar una práctica hermenéutica de dichas disciplinas no significa abrir la puerta y describir lo que hay detrás, sino crear lo que hay detrás. Esta situación presume que la propuesta hermenéutica está oculta, no está ahí dada y creada, sino que representa una 
búsqueda, una discusión y todo un proceso creativo. Tal cosa, desde la perspectiva bachelardiana es viable, pues tenemos la habilidad para develar lo oculto. En sus palabras:

los cajones, los cofres y los armarios. ¡Cuánta psicología bajo su cerradura! Hay en ellos una especie de estética de lo oculto. Para captar desde ahora la fenomenología de lo oculto, bastará una observación preliminar: un cajón vacío es inimaginable. Solo puede ser pensado. Y para nosotros [los artistas y arquitectos] que tenemos que describir lo que se imagina antes de lo que se conoce, lo que se sueña antes de lo que se comprueba, todos los armarios están llenos (Bachelard, 2000, p. 23).

Así, aprovechando la temática artístico-arquitectónica (Figura 2) que hemos citado como ejemplo; tenemos que el fotógrafo Chema Madoz toma objetos de la vida cotidiana y a partir de su representación en blanco y negro, los contrapone con otros que se asemejan para establecer vínculos que evocan una ruptura en la que luego de esa comparación, ninguno de los objetos vuelve a ser el mismo para los espectadores. Esto implica la creación de una discordia en cuanto a lo que las cosas comunican y sobre lo que ya estaba consensuado en el lenguaje. En el cual, retomando el caso del ejemplo, un atomizador de perfume, un cactus, un sombrero con agujas y una taza de café con una tira en forma de espiral, salen de su contexto y encuentran relación con obras arquitectónicas; es decir, con algo que se encontraba fuera del sentido socialmente y regularmente aceptado.

Entonces, tenemos que la comunicación se dedica a crear consensos sobre el lenguaje, trazando tangencialmente un plano de la realidad del mundo. Pero tal y como lo han mostrado Turrell y Madoz, es posible cuestionar, jugar, reelaborar y proponer sobre lo Figura 2. Lorenzo Barnó \& Agnieszka Stepien, Homenaje a Chema Madoz, 2013

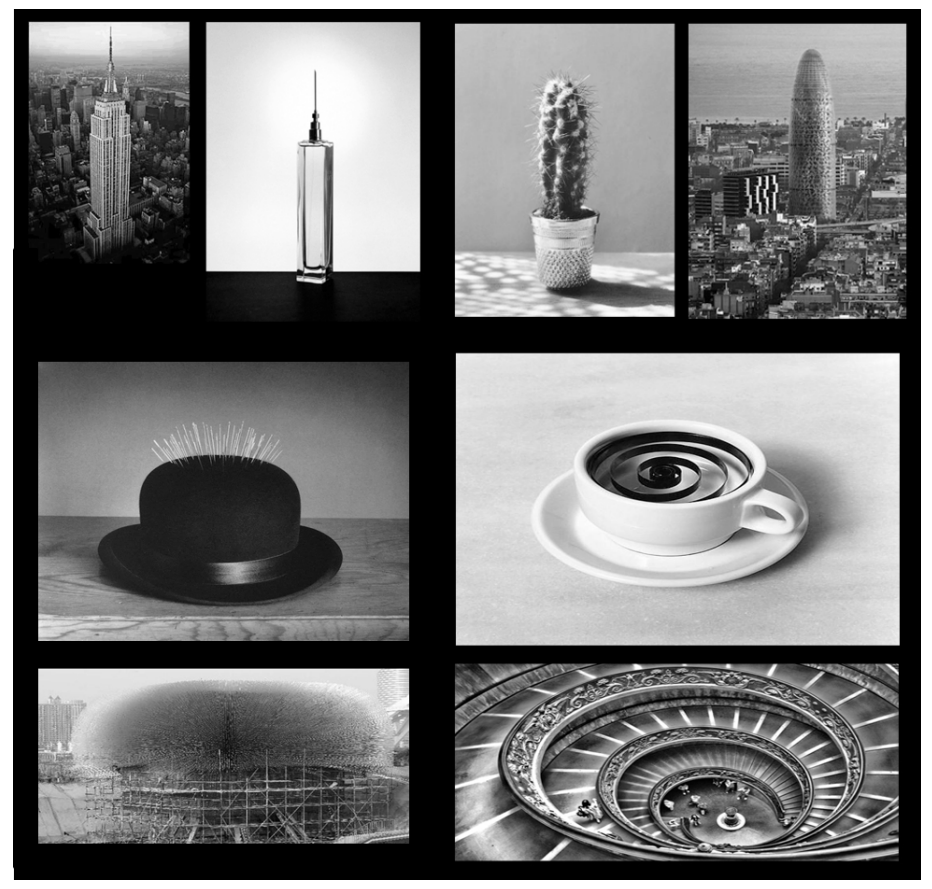

Fuente: Stepien y Barnó (11 de julio de 2013).

que se ha consensuado. 
A partir de ahí es que nuestra investigación saca provecho de la visión filosófica para ejercer una torsión sobre el lenguaje, teniendo en cuenta que "la comunicación se produce simultáneamente en diferentes niveles de la conciencia, desde la plena conciencia hasta fuera de la conciencia" (Hall, 2003, p. 10), cambiando la percepción de esa realidad común y creando una variedad de planos sobre los que las palabras se comportan como signos que adquieren un significado distinto, dependiendo del sentido con el que se construye el discurso como totalidad. De esta forma, la composición teórica es un proceso inacabado y en constante construcción. Los conceptos que conforman esa construcción, siempre tienen una noción relacional que los liga a otros. El manejo de los conceptos resulta ser un punto importante a destacar porque son estos los que articulan, reparten, distribuyen, reniegan o interceptan los objetos del mundo en diferentes esencias. Además de que todo concepto, remite a un problema de fondo, de lo que se concluye que es necesario un proceso hermenéutico que ahonde sobre estas problemáticas y las coloque en un plano de la realidad en el que se encaminen o encuentren su resolución.

En este sentido, la Filosofía al igual que el Arte o la Arquitectura, es una manera de intervenir el mundo a través de la apertura de significados y experiencias. En el caso de la filosofía, especialmente, desde la trinchera de la deconstrucción del sentido común; la búsqueda de dudas en lo aparentemente incuestionable y lo que se da por verdad sin pasar antes, por una confrontación. Así, nos adentramos a través de la filosofía en las bases argumentales para la comprensión de los procesos interpretativos previos a la materialización de las obras. Ante todo, en la construcción de un argumento, luego de reconocer todos los componentes de la realidad común, creados por el contexto, se da un primer momento de abstracción en el que la información aparece desgarrada y extraída de un plano en el que ya había adquirido un sentido -tal y como sucede con las obras de Madoz-. Sin embargo, si existe una intención y una clara asociación de ideas que se manifiesta por medio de la interpretación de los textos, es posible llegar a un momento superador que comprende todos los anteriores y da como producto una nueva realidad.

Ahora bien, el mayor desconcierto al que nos enfrentamos para poder llegar a ese momento superador es que, en este caso, no estamos trazando argumentos dentro de la gama de lo tangible -como cuando se dan pautas de diseño o se propone la resolución a un proyecto particular en un lugar determinado-, sino enfocándonos en un asunto primordial dentro de la crisis del Arte y la Arquitectura y su consecuente pérdida del sentido humano y social. Pero que es regularmente arrinconado por la práctica y a veces hasta por la teoría. Se trata de la metafísica artístico-arquitectónica, encauzada a través de la experiencia y la relación sujeto-espacio, que son la motivación de nuestro ejercicio hermenéutico considerando que:

La Arquitectura [así como el Arte] en este siglo se encuentra confrontada con dimensiones que son inconmensurables, metafísicas. A priori no puede nada contra eso, se halla en 


\section{Artículos}

la misma situación que la filosofía o las ciencias, se encuentra en edad adulta. Hay que inventar otras estrategias (Baudrillard \& Nouvel, 2001, p. 33).

Por lo anterior, este enfoque ha inspirado no solo invención teórica de una nueva perspectiva interpretativa destinada al Arte y Arquitectura. Sino también la activación de la poética como un recurso para estremecer todos aquellos valores sociales y humanísticos que se habían asentado en un rincón del quehacer creativo. Evidentemente, es posible la existencia de distintas posturas en cuanto al tema de lo poético, sin embargo, todas ellas tienen un par de asuntos en común: dan una particular importancia a la sensibilidad y la experiencia del espacio como puntos de partida. Así, la arquitecta chilena Cazú Zegers hace referencia a una Arquitectura poética como aquello que inaugura la búsqueda y creación de paisajes poéticos. A través de sus propuestas inspira a los americanos a dejar la imitación de los desarrollos ajenos a su entorno cultural y nos invita a enfocarnos en el lenguaje sensible propio de nuestras tierras, yendo al rescate de la herencia y el descubrimiento de códigos que transmiten calidad de vida sin necesidad de acudir a espacios sobre-elaborados y de alta tecnología. Ella afirma:

Yo lo llamo lujo de esencial ... Es desde la parte poética que la obra aparece: sin ella no hay obra. Esto ayuda a construir una original y no copiar ... Trabajando con la energía, la relación entre lo natural y lo urbano. La Arquitectura es un elemento de transformación social (Zegers citada por González, 2016, párr. 5-7).

Zegers ha dedicado gran parte de su carrera y sus obras a este propósito. Por ejemplo, mediante su seminario llamado Territorio Poético, defiende la poesía oculta tras lo que ella ha llamado: "leve y precario". Este ha sido catalogado peyorativamente por otros medios, como pobre y arcaico, siendo que, bajo esta línea de pensamiento se niega la postura poética que responde a la creación de atmósferas sensibles al paisaje y el ser humano. Desde la perspectiva de Cazú, por el contrario, no hay pobreza en los materiales, ni modos anticuados en la Arquitectura, sino un reconocimiento de la carga poética sobre la manera en la que es aprovechada esa levedad y ese precarismo. En efecto:

La arquitectura de Cazú es una arquitectura que lleva al máximo la comprensión del entorno y que lleva al máximo la comprensión del habitar, [señala Fernando Marín, Decano de Arquitectura, Diseño y Construcción de la Universidad Mayor] ... Cazú Zegers definió su arquitectura como una propuesta de bajo contenido tecnológico y de alto impacto poético y de experiencia. ... Es un método poético, que comienza con un signo sobre el territorio, que más tarde se vuelve figura y que luego es una forma (Cazú Zegers presentó su arquitectura poética en la U. Mayor, 28 de junio de 2012, párr. 1-3).

Refugiándonos en la posibilidad de una poética del espacio, el hermeneuta es a la intimidad lo que la poesía es a la casa. Bachelard dice sobre la casa que: "incluso reproducida en su aspecto 
exterior, dice una intimidad" (Bachelard, 2000, p. 78). Efectivamente, la lectura interpretativa del hermeneuta, debiera ser así, capaz de extraer lo más íntimo, hasta de lo que parece superfluo.

En ese sentido, dos de las obras de Madoz son representativas de aquello que la hermenéutica hace (ver Figura 3). Primero, cuando ante la realidad ya escrita, es decir, la realidad dada, la interpretación de los textos nos permite extraer la tinta de esa realidad, que sería su esencia, para avocarnos a escribir algo distinto. En segundo lugar, cuando al profundizar "en medio" de los grandes conceptos del Arte, la Arquitectura y la Filosofía, nos encontramos con intertextos o también, con mensajes ocultos que revolucionan, inspiran o ayudan a crear enlaces que alteran el sentido de los conocimientos preestablecidos.

Figura 3. Chema Madoz, Libro

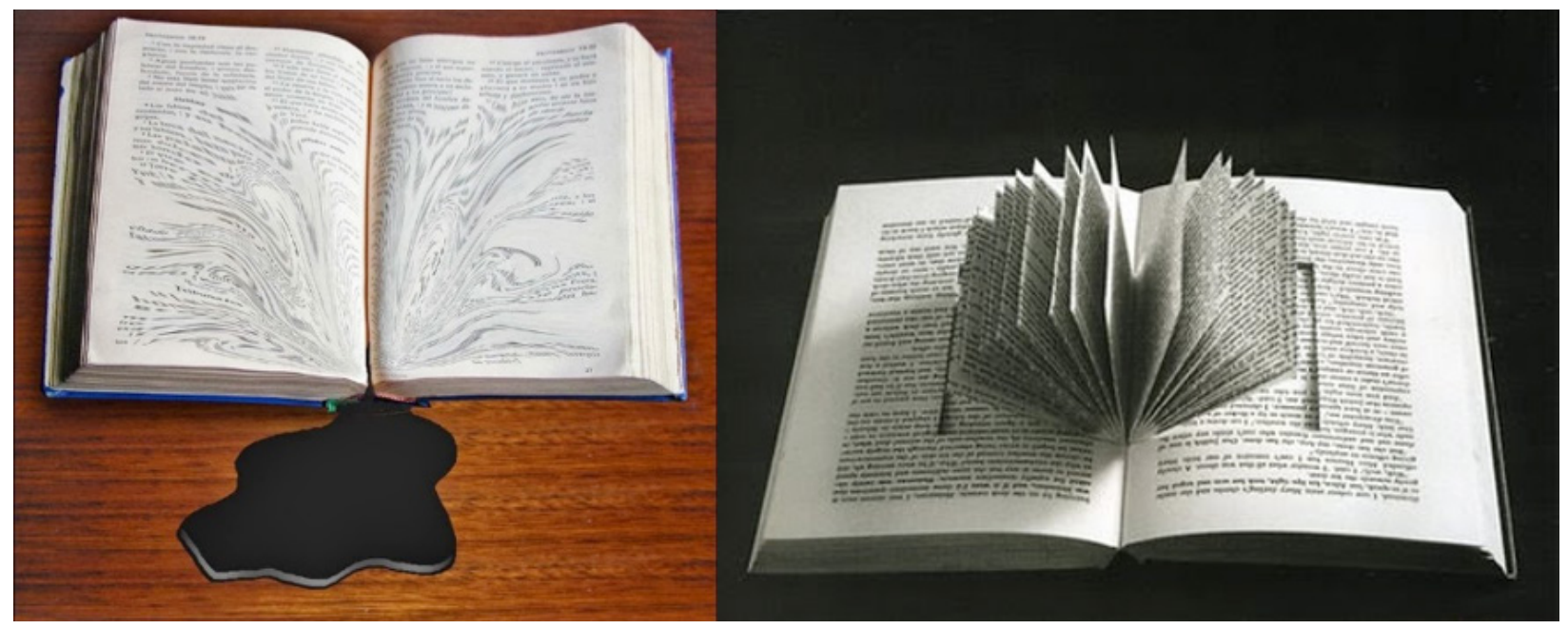

Fuente: Molero (7 de octubre 2013).

Tal efecto de la interpretación de los textos es asumido por Hall al decir: "la computadora es una prolongación de una parte del cerebro, el teléfono prolonga su voz, la rueda prolonga pies y piernas. El lenguaje prolonga la experiencia del tiempo y el espacio, y la escritura prolonga el lenguaje" (Hall, 2003, p. 9), de forma que, si la Arquitectura es un lenguaje que nos refiere a experiencias espacio-temporales -como textos- y dicho lenguaje se encuentra en cambio constante, es probable encontrar en él intertextos y esencias que nos permitan construir nuevos enlaces para "reescribir" el gran libro de la Arquitectura.

Debemos tener bajo consideración que, por muchos años, las concepciones teórico-prácticas de la Arquitectura se han acumulado y generalizado, creando una gran masa sólida que funda en nuestra disciplina un actuar casi dogmático en torno a la resolución del diseño 
y la construcción. Por lo que "reescribir" viene a ser una manera de describir el desmoronamiento de esa gran masa sólida de conocimientos rígidos dentro de un proceso capaz de volver sobre sí mismo para lograr que las ideas se mantengan en movimiento dinámico. Baudrillard y Nouvel amplían:

Lo que es del orden de las recetas previas, dicho de otro modo, de la Arquitectura, se vuelve absolutamente estúpido. Desde el momento en que integras un modelo estructural en ese sistema, se vuelve absurdo. ... la Arquitectura ya no es más la invención de un mundo ... no puede tener otro objeto que el de transformar, el de modificar esta materia que ha sido acumulada (Baudrillard \& Nouvel, 2001, p. 32).

Por tal motivo, para la consideración de los procesos interpretativos que preceden a la creación de una obra, partimos de una visión que nos permite adentrarnos en el proceso bajo el cual las ideas artísticas y arquitectónicas, surgen y continúan generando enlaces para ampliar el conocimiento. Así, queda descrito el proceso, en el siguiente diagrama:

Diagrama 1. Generalidad del Proceso Interpretativo

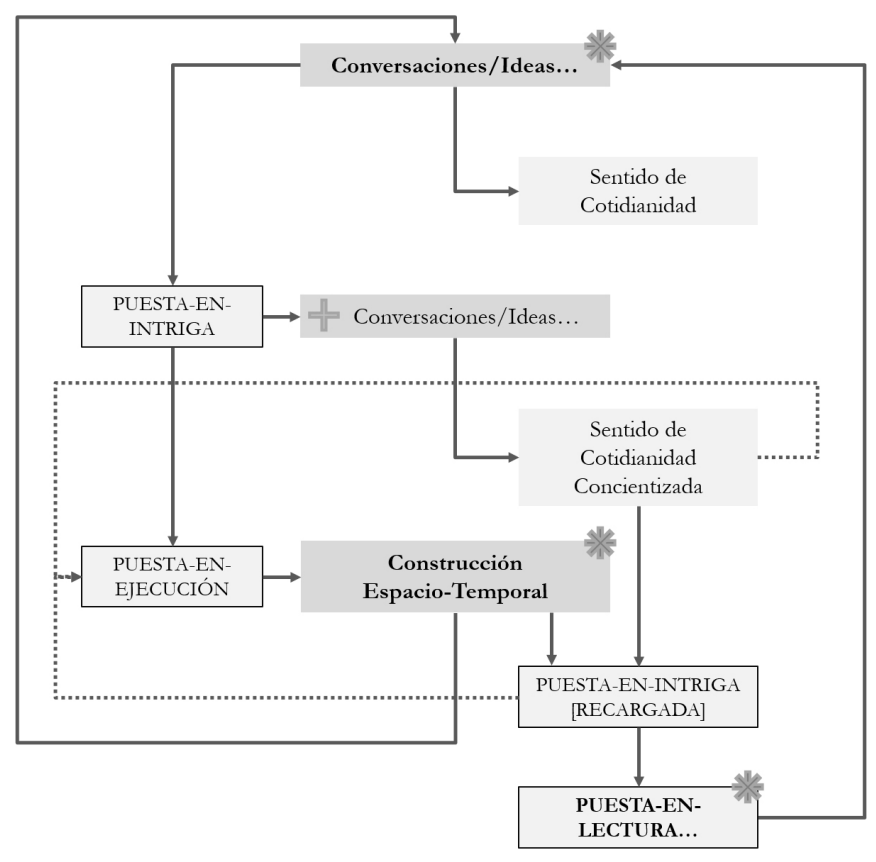

Fuente: Elaboración propia

Es a través de este encadenamiento de ideas que encontramos la relación entre lo que sucede en la vida cotidiana, las obras generadas desde el Arte y la Arquitectura, y la continua lectura y relectura de las ideas. Tenemos entonces que, en la vida cotidiana con base en nuestras propias vivencias y las de las personas que nos rodean surgen "conversaciones e ideas" que tienen que ver con nuestras diligencias diarias, intereses, problemas y demás modos de interactuar con el mundo. Entre las "conversaciones e ideas" se generan dos productos reconocibles: por un lado, el "sentido de cotidianidad" que resulta de aquellos temas recurrentes y triviales, como puede ser una discusión sobre el clima, el tráfico o el cumplimiento de alguna labor en particular. Y, por otro lado, la "puesta-en-intriga" que vendría a ser el resultado o mejor dicho la reacción ante ciertas "conversaciones e ideas" que nos generan una incógnita, nos despiertan una inquietud o nos hacen adentrarnos en un ejercicio de reflexión que se profundiza generando más asociaciones mentales en torno a lo sucedido. 
Cabe destacar que, si analizamos la sensación de intriga desde la construcción del tiempo en forma de relato, la intriga representa aquella secuencia (ordenada o desordenada) de acontecimientos que generan el nudo argumentativo. De esa manera, logran infundir la tensión y el interés en los lectores, preparándolos para un desenlace, que en este caso sería la "propuesta de una obra" o el surgimiento de "más conversaciones e ideas". Ahora bien, desde la Arquitectura, y las artes en general, es reconocible la existencia de un espíritu sensible hacia la puesta-en-intriga, ya que es gracias a esta tendencia a problematizar sobre los hechos cotidianos que los artistas y arquitectos nos adentramos en una dimensión alterna de la realidad, en la cual encuentran cabida la creatividad y la innovación como modos de exacerbar los significados en las situaciones más rutinarias. De hecho, Holl confirma:

La Arquitectura tiene el poder de inspirar y transformar nuestra existencia del día a día. El acto cotidiano de agarrar el pomo de una puerta y abrirla hacia una estancia bañada por la luz, puede convertirse en un acto profundo si lo experimentamos con una conciencia sensibilizada (Holl, 2011, p. 8-9).

Este despertar de una conciencia sensibilizada del que habla Holl, lo podemos ejemplificar situándonos sobre la concientización de la existencia a través de la experiencia trascendental del espacio y el Arte. A partir de ahí, se nos presenta uno de los grandes motores del Arte y la Arquitectura, que tiene que ver no solo con la habilidad de artistas y arquitectos para llegar a la puesta-en-intriga. Sino también con la posibilidad de que, con base en los productos de dicha fase, cada disciplina puede intrigar, hacer cuestionar, interesar, asombrar y lanzar interrogantes que afectan a los otros y los sacan de su sentido de cotidianidad. Entonces tenemos que la puesta-en-intriga nos conduce a otros dos productos: la "puesta-en ejecución" y la estimulación de "más ideas y conversaciones". En el primer caso, nos encontramos con que existen una serie de circunstancias: educativas, sociales, económicas y temporales, entre otras que pudieran existir, que aunadas a una gran motivación por hacer algo ahora o a corto plazo, nos conducen a concretar una respuesta a las problemáticas reconocidas, a través de una construcción espacio-temporal, llámesele intervención proyectual, obra de arte o forma escrita. En el segundo caso, se trata de una situación de la que ya nos hemos hecho conscientes y que se ha destacado, pero que es muy compleja y no contamos actualmente con todos los medios para aportarle una respuesta concreta inmediata (o al menos a corto plazo). Además, el tema nos incita más a continuar generando interrogantes que a concretarlo todo en un resultado específico.

No obstante, esto no significa que dichos temas que incitan a "más ideas y conversaciones" se mantengan en un estado abstracto o como una habladuría, ya que es gracias a ello que arribamos al "sentido de cotidianidad concientizada" por medio del cual se crean exposiciones, ponencias, grupos de discusión y de interés, así como organizaciones que, finalmente, legitiman, dan poder a las ideas e informan a otros grupos de personas hasta que logran crear 
conciencia sobre el tema o problemática que tratan y, eventualmente, (pero no necesariamente) pueden llegar a una puesta-en-ejecución.

Luego de eso, nos encontramos que debido a la legitimación que adquieren los fenómenos cuando han ameritado la creación de una obra arquitectónica, un libro, un cuadro o una organización, todas las intenciones de cambio, mejora y experimentación ante las situaciones que nos generaron la puesta-en-intriga son ahora transmitidas y se ramifican sobre diversas personas que se suman a la "puesta-en-intriga (recargada)". Este último concepto se podría describir como el surgimiento de una sociedad que "no se contenta con los hechos; descubre en ellos valores y significados. Escucha atentamente las cosas, que son siempre algo más que simples cosas porque le transmiten mensajes que tiene que descifrar" (Boff, 2002, p. 123).

Así, este recargamiento de la curiosidad, el interés, el asombro y el deseo de cambio nos puede conducir a ejecutar un proyecto concreto. Sin embargo, su mayor retribución está en que nos permite llegar nuevamente al inicio del proceso interpretativo, pero esta vez desde una perspectiva que engloba todos los productos anteriores. Por lo tanto, tiene un mayor potencial para proponer una transformación. Se trata de la "puesta-en-lectura", a la cual también podríamos llamar, según Levin, "la mirada aletheica".

En su concienzudo libro The opening of vision: nihilism and the postmodern situation, David Michael Levin diferencia entre dos tipos de visión: "la mirada asertórica" y "la mirada aletheica”. En su opinión, la mirada asertórica es estrecha, dogmática, intolerante, rígida, fija, inflexible, excluyente y no conmovedora, mientras que la mirada aletheica, asociada a la teoría hermenéutica de la verdad, tiende a ver desde una multiplicidad de puntos de vista y perspectivas, y es múltiple, pluralista, democrática, contextual, inclusiva, horizontal y generosa. Tal como sugiere Levin, hay señales de que está surgiendo una nueva manera de mirar (Pallasmaa, 2006, p. 35).

Esta manera de mirar, es la de mirar hermenéuticamente. Es decir, hacer una lectura que, aporta nuevos significados a las propuestas concretas de manera que, se puedan reingresar en el mundo de las "ideas y conversaciones". En efecto, las obras literarias, artísticas y arquitectónicas se encuentran incompletas en la medida en que sus contenidos se mantienen en suspenso hasta que son leídos por el otro. Esa significación que el lector entrega al texto literario configura a este mismo como texto literario, de modo que la observación de una segunda persona se convierte en un elemento necesario, la recepción actúa como clave esencial para la trascendencia de la creación (Cordón, Gómez \& Arévalo, 2013, p. 15).

El tiempo es constantemente prefigurado en nuestras conversaciones cotidianas, pero es también configurado (construido) cuando se convierte en relato de alguna forma literaria y finalmente transfigurado cuando es leído y releído. Lo mismo sucede con el espacio que se 
prefigura en nuestras ideaciones sobre el habitar. Se configura en obras arquitectónicas proyectadas o edificadas y se transfigura gracias a su lectura que viene a ser una interpretación sensible y, en especial, sensata de lo que tales proyectos significan. Al respecto, Boff menciona:

Si descubrimos, por ejemplo, una grieta en la pared, sería engañoso e irresponsable coger cemento y cal y limitarse a taparla. ¿No habría que examinar los cimientos que sostienen al edificio, que no suelen estar a la vista, y detectar ahí la causa de la grieta y arreglarla desde la base? (Boff, 2002, p. 22)

Y efectivamente, esto es lo que hace la hermenéutica, un ejercicio crítico y sensato de observación y asociación de ideas, en el cual los textos (construcciones espacio-temporales) no se interpretan con la finalidad de forzarlos a calzar dentro de un discurso coherente. Más bien propone que de ser necesario remover conceptos desde sus cimientos se hará en función de una reedificación que preserve la generación de un sentido y un significado verdadero, independientemente de sí es positivo o negativo, sobre las obras (ver Diagrama 2).

Diagrama 2. Relación Dialéctica entre el Sujeto y el Objeto

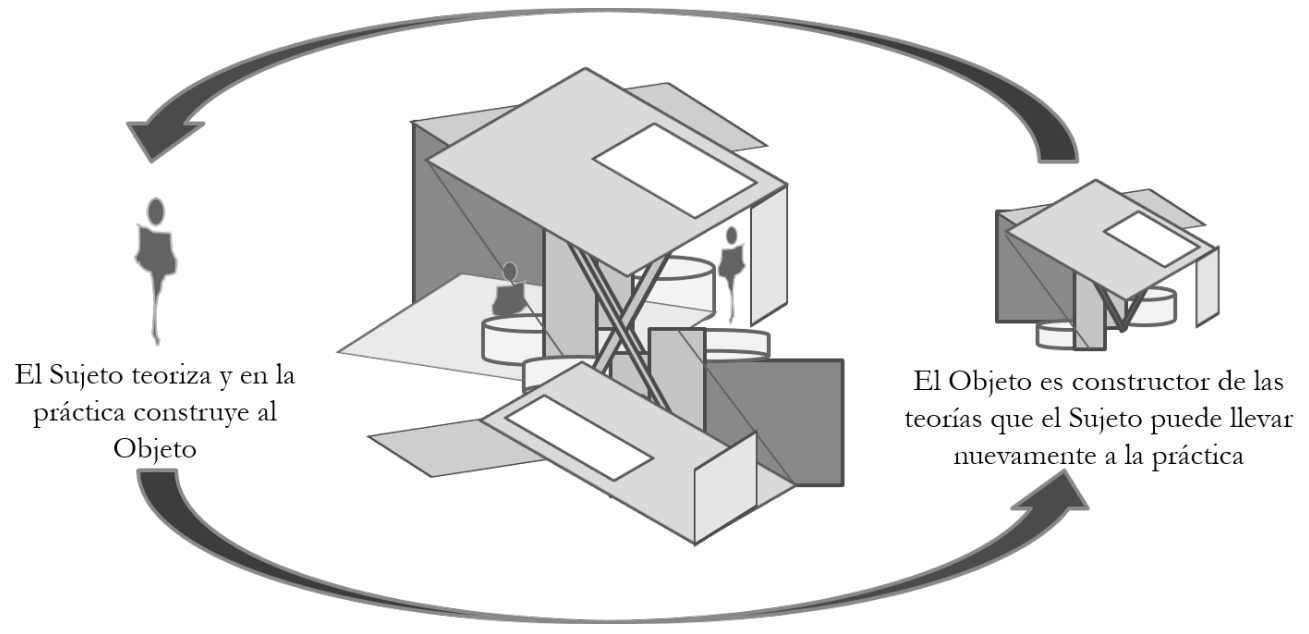

Fuente: Elaboración propia

Es debido a la puesta-en-lectura que las obras sobrepasan su conclusión. Sobre ellas y entre ellas se edifica una red de ideas que les permite ir más allá del tiempo y el espacio, ser inspiración de nuevos modos de vida, fundamento de evaluaciones críticas o detonantes de la transformación teórica y práctica, en la que el límite entre ambas se difumina y, finalmente, se pierde. Entonces, reconociendo que hemos codificado la existencia de las cosas para hacerlas comprensibles -tal y como sucede con las letras, los números y las unidades de medida, entre otros-, ahora también tenemos entendido que es posible recrear distintas versiones de la realidad existente a través de la decodificación hermenéutica. Lo que se interpreta viene a ser un encuentro entre 
la realidad conocible y un ser humano con un cierto grado de capacidad para reconocer dicha realidad conocible. Al descubrir lo extraordinario en ella, el resultado es una recreación consciente de lo que es vital -en cualquier sentido- dentro del objeto que es interpretado. Entonces:

podemos leer solo para informarnos o por placer, pero también podemos leer para comprender, con la finalidad de conocer, para lo cual se requiere, [según Gallardo, 1982, p. 8], 'haber desarrollado habilidades ligadas a la capacidad de relacionar ideas y de comparar opiniones diversas acerca de un mismo tema; lo que nos lleva de vuelta a la idea de que la lectura es una actividad dinámica por medio de la cual se adquiere el conocimiento (González, 2007, p. 5-6).

Por este motivo, la puesta-en-lectura es el clímax, no solo del proceso interpretativo, sino de la reivindicación del rol humanista y humanizador del Arte y la Arquitectura que recarga nuestra intriga por todo lo poético y trascendental en la experiencia del espacio-tiempo. "El humanismo no es un sistema, es una refundación permanente, una lucha. Es una 'transvaloración' de valores, como decía Nietzsche. Esto supone conocer esos valores, apropiárselos y cuestionarlos" (Larroque, 2015, párr. 5). Es comprender el proceso creativo no desde el problema determinado que encuentra su respuesta en la obra creada, sino, desde la concepción de una cotidianidad que acumula y gesta experiencias significativas que nos permiten reflexionar y activar nuevas versiones de lo prescrito.

Por lo tanto, construir un relato, una obra artística o un espacio, desde la hermenéutica, se traduce en un proceso de figuración y formación espacio-temporal de un conjunto de textos. En donde el quehacer no se inscribe únicamente dentro de las habilidades propias de un oficio, sino que tiene un trasfondo histórico en el que se han acumulado conocimientos, que nos muestran que se trata de una compleja mezcla de Filosofía, Ciencias sociales, Psicología, Historia, Física y Matemática, entre otras. Pero también, que los fenómenos perceptuales y culturales solicitan de las Artes y la Arquitectura, un conocimiento que acompañe el saber-hacer.

Este conocimiento es la parte interpretativa, que es regularmente obviada al punto de que el Arte y la Arquitectura se enseñan más como un hacer, que como un saber-pensar o saber-interpretar. De hecho, Gómez en un artículo dice que Heidegger apunta: "el mundo no nos sería accesible si no tuviésemos una pre-comprensión de él, como totalidad de significados. ... [De manera que] El comprender es el modo original de ser-en-el mundo" (Gómez, 2009, p. 91). Esto quiere decir que la comprensión, hasta cierto punto, se asume como parte de la existencia y así al existir tenemos implícita ya una interpretación previa. No obstante, esto no significa que nuestra habilidad interpretativa está dada, pues el hecho de capturar sensitivamente un espacio y extraer cierta información del mismo es solo un acto instintivo. Es, en efecto, un buen punto de partida, pero carece de la inteligibilidad y la reflexión propia de un proceso hermenéutico. 
Entonces, la hermenéutica no es algo que se pueda asumir, sino un tópico a desarrollar, pues la interpretación inmediata o que se tiene de previo puede diferir en mucho de los productos de un proceso interpretativo completo, que conlleva conjuntos de fases en las que los significados se profundizan y transforman. Curiosamente, el asunto interpretativo está presente en las decisiones y el desarrollo general de los procesos de diseño, así como, en el enfoque de la crítica y la literatura asociadas a la Arquitectura. Aun así, permanece entre las sombras y es poco discutido. En todo caso, sin quererlo o, mejor dicho, inconscientemente; las habilidades interpretativas se despiertan y se comienzan a afinar a lo largo de la formación de los arquitectos que aprendemos a pensar la Arquitectura en el rol de traductores y mediadores entre los códigos de una comunidad o conjunto de personas y los códigos arquitectónicos. Pero, a la vez, desconociendo todo lo que en realidad implica llevar estos conocimientos a su máxima expresión a través de la hermenéutica.

Hasta ahora, los arquitectos no hemos ahondado en la concepción de las variables asociadas al espacio como textos. Las pautas o, incluso, intuiciones que utiliza la Arquitectura en el ámbito interpretativo son solamente evidencia de nuestras capacidades interpretativas naturales, que para desarrollarse requieren de la comprensión del texto-mundo como un proceso que es posible explicar, desmenuzar e insertar en la academia. De esta manera el ejercicio de la Arquitectura se visualiza como una alternativa a favor de la reconstrucción conceptual y el derrocamiento de convencionalismos. Recordemos que los productos y modo de actuar desde la hermenéutica, no coinciden en su totalidad con el empirismo del método científico. Desde ahí, esta propuesta resulta en una disociación respecto a la manera tradicional de pensar, estudiar y ejercer la Arquitectura. Bachelard en su Poética del Espacio agrega:

Fieles a nuestros hábitos de filósofo de las ciencias, habíamos tratado de considerar las imágenes fuera de toda tentativa de interpretación personal. Poco a poco, dicho método, que tiene a su favor la prudencia científica, me ha parecido insuficiente para fundar una metafísica de la imaginación (Bachelard, 2000, p. 9).

En este sentido, el acercamiento que en esta investigación hemos hecho, al estar vinculado con fenómenos metafísicos como la experiencia y la visualización del espacio, no podría evadir la presencia del componente subjetivo, que ya de todas formas, es parte del enfoque hermenéutico. En este, cada obra escrita, esculpida, pintada o edificada, no es una ley irrefutable sino una certeza contingente que puede ser leída, recreada y adaptada a lo largo del tiempo.

\section{Referencias}

Augé, M. (2000). Los «No Lugares» Espacios del Anonimato: Una antropología de la Sobremodernidad. Barcelona: Editorial Gedisa. 
Bachelard, G. (2000). La Poética del Espacio. Buenos Aires: Ed. Fondo de Cultura Económica.

Baudrillard, J. \& Nouvel, J. (2001). Los objetos singulares: arquitectura y filosofía. Buenos Aires: Ed. Fondo de Cultura Económica.

Boff, L. (2002). El Cuidado Esencial: Ética de lo Humano Compasión por la Tierra. Madrid: Editorial Trotta.

Molero, E. (7 de octubre 2013). Re: Poesía visual [blogspot]. Recuperado de http://elenamolero. blogspot.com/2013/10/poesia-visual.html

Cazú Zegers presentó su arquitectura poética en la U. Mayor. (28 de junio de 2012). Diario Mayor. Recuperado de https://www.umayor.cl/diarioomayor/index.php?option=com_content\&view=article\&id=1836\%3Acazu-zegers-presento-su-arquitectura-poetica-en-la-u-mayor\&catid $=7 \&$ Itemid $=1$

Cordón, J.; Gómez, R. \& Arévalo, J. (2013). Documentos Electrónicos y Textualidades Digitales. España: Ediciones Universidad de Salamanca. Recuperado de: https://books.google.co.cr/ books?id=Xl7UAgAAQBAJ\&printsec $=$ frontcover\# $\mathrm{v}=$ onepage \&q\&f=false

Go See- Germany: James Turrell's “The Wolfsburg Project," at Kunstmuseum-Wolfsburg through April 5th, 2010 (10 diciembre 2009). Recuperado de http://artobserved.com/2009/12/ go-see-germany-james-turrells-the-wolfsburg-project-at-kunstmuseum-wolfsburg-through-april-5th-2010/

Gómez,R.(2009). ExistenciayComprensiónen Heidegger. Intersticios, 14(30), 89-98. Recuperado de https://www.academia.edu/2048555/Existencia_y_comprensi\%C3\%B3n_en_Heidegger

González, A. (5 de mayo, 2016). Cazú Zegers: La Unión Entre el Poema y la Infraestructura. Revista Perfil. Recuperado de http://www.revistaperfil.com/gente/Cazu-Zegers-union-poema-infraestructura_0_951504842.html

González, I. (2007). Reconociéndo(nos): Sobre la Lectura. San José: Editorial UCR.

Hall, E. (2003). La Dimensión Oculta (Trad. F. Blanco). México: Siglo Veintiuno Editores.

Heidegger, M. (2009). El Arte y el Espacio (Trad. J. Escudero, primera edición 1969). Barcelona: Herder Editorial, S.L.

Holl, S. (2011). Cuestiones de Percepción: Fenomenología de la Arquitectura. Barcelona: Editorial Gustavo Gili.

Larroque, J. (24 de setiembre, 2015). Julia Kristeva: "El humanismo no es un sistema, es una refundación permanente". Revista de Cultura Independiente y Plural. Recuperado de http://www. elcultural.com/noticias/letras/Julia-Kristeva-El-humanismo-no-es-un-sistema-es-una-refundacion-permanente/8366 
Pallasmaa, J. (2006). Los Ojos de la Piel: La Arquitectura y Los Sentidos. Barcelona: Editorial Gustavo Gili.

Stepien, A. \& Barnó, L. (11 de julio de 2013). Re: Post homenaje a chema madoz [blogspot]. Recuperado de http://www.stepienybarno.es/blog/2013/07/11/post-homenaje-a-chema-madoz/

Vattimo, G. (2007). El Pensamiento de los Débiles. Revista de Filosofía, A Parte Rei, (54). Recuperado de http://serbal.pntic.mec.es/ cmunoz11/debiles54a.pdf 